of a timber waggon laden with about five tons' weight of timber, he fell down behind the horse and between the fore-wheels, and in attempting to escape by the side from under the waggon one of the hinder wheels passed over both his legs. He was tak en home some distance, and attended to by a medical man, who found the patient suffering from a profuse bæuorrhage, proceeding from a ragged wound in the lower and back part of the right thigh, at the upper boundary of the popliteal space, caused by the protrusion of the fractured ends of the bones. There was some trouble in checking the bleeding, and hare-lip needles were made nse of, several being passed in different directions through the wound, which was brought together by twist ed sutures. The accident occurred late in the evening, and the patient was not brought to the hospital, a distance of about twelve miles, until the next day.

On admission be was in a state of great prostration from pain and loss of blood. A long splint was very carefully applied with a many.tailed bandage, and the limb placed upon pillows ; stimulants, beef-tea, and opium being ordered. The following morning, in consequence of the increasing tension, the needles were removed, when a considerable quantity of decomposed blood and serum escaped, with fetid gas; whilst the lacerated hamstring muscles protruded through the wound. It was now apparent that a splint could not be used in conse quence of the damaged state of the limb, and the impaired vitality, which seemed to threaten gangrene. The splint was therefore removed, and the limb merely laid upon pillows, which were covered with waterproof material, and so arranged as to allow an interval corresponding to the position of the wound, which was surrounded with water dressings, the whole being steadied by means of long sand cushions.

In a few days there was sloughing of the wound and cellular tissue in the course of the muscles, with foul discharge; also diffuse suppuration beneath the integuments, extending up to the trochanter. This was freely opened. Upon the inner side of the left leg there was a contased wound, about seven or eight inches in leagth by about three in breadth, extending above and below the knee, which in the course of a few days assumed a very unhealthy character. Early incisions were made; but the entire surface sloughed, completely denuding the muscles and tendons of the part. The knee in the meanwhile had been flexed to an acute angle to relieve pain. This was remedied as soon as possible, and the joint retained in a straight position. The wound was dressed with broad strips of lint, spread with resin cerate, which were carried round the circumference of the limb, and clothed with cotton wadding.

For a week or ten days the patient took little or no nourish ment, and was sustained chiefly upon brandy and opium, his condition being most critical. In consequence of the large amount of discharge from both limbs, and of its offensive character, considerable difficulty and trouble was experienced in the dressing. This, however, was much diminished by the use of a double-framed bed, the sacking of which was made up of bands four inches in breadth, fixed at the sides, and movable at will. Two or three of these bands were removed as required; and when the upper part of the bed-frame was raised in the ordinary way, the fractured limb could be washed and dressed from below. It, however, required great care to prevent the fractured extremities doubling upon each other, and thus pro. truding through the wound. This was obviated partly by the arrangement of the pillows and by the use of a double perineal band fixed to the head of the bed, whilst the foot, carefully covered in thick folds of cotton, was secured by a broad bandage to the bottom of the bed. Little else could be attempted for some time than to dress the wounds and induce them to heal, and to support the patient's strength. No effort was made to apply a splint until a sound healthy nutrition was re-established.

At the end of two months some callus was developed, and the wound contracted. Support was now given by means of gutta.percha applied to the anterior surface. Everything henceforward progressed favourably, and about the beginning of the fourth month the patient could raise the limb slightly. Loose bone was now discovered through a sinus opposite the seat of fracture. The cicatrix was opened, and a portion of the shaft of the bone, about an inch and a half in length, with several smaller pieces, were removed.

The patient was discharged on the 18 th of October, with a very useful limb; a high-heeled boot compensating for the loss of length.

A few points as to the immediate treatment of such a case s zem to suggest themselves for consideration. As to the best mode of checking the hæmorrhage, of course any vessels $w$ ithin reach should be ligatured or twisted; but as there would in such an extensive injury be rupture of many small vessels, arteries as well as veins, impossible to control by such means, and from which extensive hæmorrhage may take place, we must resort to pressure; and the method most suitable seems to be the introduction of narrow strips of oiled lint within the wound by means of the finger, so as to completely fill it from the bottom; a compress should then be applied, and secured by strapping or a few turns of a bandage, due regard being $o b$. served as to the amount of pressure used. There seems to be an advantage in using oil : the lint can be more readily intro. duced, and it adapts i1self more easily to the interstices; moreover, I believe it has a soothing effect, and, what is important, the lint can be more readily removed without causing a recur. rence of the bleeding. The nse of sutures in lacerated wounds rarely or never answers, more especially where the surrounding parts have been much damaged and the wound is deep. Hæincrrhage goes on within the wound, and the effused blood finds its way into the cellular membrane and between the muscles, in many instances decomposing and causing the death of already damaged tissues, besides exerting an outward pressure which must greatly aggravate the mischief already existing in the integument itself.

The importance of early attention to the position of the left limb, and in straightening the knee, must be obvious. Nevertheless it is remarkable how often this rule of treatment is overlooked. The records of orthopædic surgery doubtless could exhilit many instances of such cases; whilst I myself have operated upon several deformities arising from a similar cause. Dorset, Angust, 1863.

\section{ON A CASE OF}

\section{INGUINAL HERNIA TREATED SUCCESS- FULLY ON PROF. CHISHOLM'S METHOD.}

\section{BY JAMES J. DICKINSON, EsQ, ASSISTANT-SURGEON, BENGAL MEDICAI, SERVICE.}

THE very great interest that attaches itself to every success. fully treated case of inguinal hernia by the radical methods in. troduced by Prof. Wiitzer and Mr. John Wood, induces me to believe that the publication of the subjoined case may prove acceptable to the profession at large-1st, on account of its complete success; 2ndly, because it is simpler than either Wiutzer's or Wood's, as will be hereafter shown; and 3rdly, as $I$ am under the impression the operation has as yet been but rarely, if ever, performed in India.

The man who was operated upon was a Bhelstee, aged thirty, and his history is as follows:- - He was ruptured in the cold season of 1856 , in consequence of slipping while descending a steep hill near Cashmere. Immediately he felt as if something had given way, and on placing his hand over his right groin, discovered a small tumour there. This gradually increased in size, took a downward direction, and ultimately descended into the scrotnm. He states that from the day of the accident till within a few days of having the operation performed he has regularly pursued his avocation, and that, with the exception of one or two obstinate attacks of constipation, he has enjoyed uninterrupted good health.

When he first presented himselr to me in April last, I lost no time in writing off to my friend, Dr. Bourne, to get me a neerle constructed similar to the one described by Professor Chisholm; but from the time it necessarily takes to get anything made in India as compared with England, some slight delay occurred, and we were ordered to march from Segoolee to Gwalior, a distance of 500 miles. The man, however, was so anxious to have the operation performed, that he marched the whole of the way with us!

On examining him, I found he had a large inguinal hernia of the right side, which completely filled the scrotam. With gentle pressure the whole of the gut could be easily returned: and on pushing the flabby scrotum up before the forefinger, it could be passed through the tendinous aperture, more than an inch in diameter, into the abdomen, and the pillars of the external ring could be distinctly felt. The man himself was a spare man, though in good condition; and I mention the fact because I am of opinion that pari passu with stontness, so will the difficulty of the operation be enhanced, and so will needles of various sizes and curves be required.

On the 27 th of May I performed the operation, having on the previous day given him a dose of castor oil. After the case 
had been carefully examined by my friends, Assistant.Surgeon Jackson, of H.M. 13th Light Infantry, and Dr. Caird, of the Camel Corps, by both of whom I was ably assisted, I proceeded to operate, the patient being under the influence of chloroform. The mode of operating is as follows: "The scrotum having been invaginated upon the finger, as the only mode of guiding the needle in its passage, a long strong curved needle, fixed firmly in a bandle and armed with silver wire, guided by the finger, transfixes the scrotum at the apex of the invaginated portion, passes through the internal column, and appears through the sinin of the abdomen, when one end of the wire is drawn out. The point of the needle is then drawn backwards, and disappears again in the canal. Its direction is then changed. Whilst still embedded in the scrotum and guided upon the finger, its point is made to traverse the external column of the ring near Poupart's ligament, lifting the skin of the abdomen. By gliding the skin upon the needle, the point appears through the small puncture made by the first passage of the needle, when the other end of the wire is seized, and the needle is unarmed and withdrawn through the scrotum. The finger is now removed from the canal, and the two ends of the wire being drawn upon the loop, it dissects the cellular tissue up to the columns, which it hugs closely. By twisting the ends of the wire the columns are felt approaching, until they are brought into such close apposition as to allow nothing to pass between them; the spermatic cord in its exit filling up all the available space remaining of the ring. When the ring is felt closed, the twisted wire is drawn firmly outwards, and clipped off as close as possible to the skin, so that when traction on the skin of the abdomen is removed, the gliding back of the integuments to their normal positions conceals completely the ends of the small loop of silver wire." This is the description of the operation as given by Prof. Chisholm. The operation which I performed was, but with one slight modification, precisely similar. Those who witnessed the operation were much struck, on passing their forefingers up the canal, to find how very distinctly the pillars could be felt approximating as the wire was being tightened; and when it was tied, and the ends cut off, a perfect plug could be felt, presenting an impassable barrier to the egress of any portion of gut.

The progress of the case was everything that could be desired. For the first two days there was slight pain over the abdomen, which was subdued by small doses of opium; and there was also a good deal of thickening of the cord, which subsided after a time. The small wounds healed slowly; nor need this surprise us when we remember that the thermometer stood at $105^{\circ}$ in the house.

On the thirteenth day after the operation he was able to rise from his bed and obey the calls of nature; and on the twentyfifth day he walked from the hospital to my house and back again, a distance of a mile and a quarter, without suffering much fatigue. On the 20 th of June (twenty-four days after the operation) he was discharged, being at that time able to draw as much water from the well as he required for his own use.

Remarks. - The operation as performed by me differed in one point from Prof. Chisholm's - viz., that instead of puncturing the scrotum at once with the needle. I made a sljght incision with a scalpel through the fascia of the scrotum, and then passed the needle in. This suggestion emanated from my friend Dr. Jackson, who believed that it would render the performance of the operation less obscure, an opinion in which $I$ agree. The only difficulty in the operation is, after having secured the inner pillar and withdrawn the needle, to secure the onter pillar, which requires a peculiar manœurre. I think it should be secured a line or two lower than recommended by Professor Chishoim, thereby obtaining a more perfect approximation of the parts by reason of the greater purchase that is acquired.

The needle $I$ use is six inches long, and firmly fixed into a handle, in appearance resembling a common suture needle, having, however, on its convex surface a groove sufficiently deep for the silver wire to be perfectly embedded in, and thus avoid a resisting surface, which would be the case were this groove not there. I would recommend intending operators to have a set of four needles, similar to those my friend, Dr. Bourne, is having constructed for me, and from whose firm (Messrs. Bathgate and Co.) they are obtainable. I have purposely avoided commenting on the class of people for whom I think this operation applicable, as from a solitary though successful case it would be all but impossible to draw any inferences, and were we to do so they could only be regarded in the light of postulates.

In conclusion, the question will be naturally asked, Does this operation of Professor Chisholm's present greater advan- tages than either Witzer's or Wood's? My answer is, Yes, it does. And I think a careful perusal of the three methods will satisfy practical surgeons of the truth of my assertion. First, it is superior to Witzer's on account of its greater simplicity by reason of the absence of all complicated apparatus (no mean point to be borne in mind by military surgeons stationed hua. dreds of miles away from any city), as well as in the procedurs itself; secondly, on account of the permanency of the plug, due to the presence of the silver wire always remaining there; and, thirdly, no truss being required in the after-treatment. With reference to Wood's operation, of which it may really be considered a modification, I think hereafter, when we have more data to go upon, that if it does not altogether supersede it, it will at least be found to have a sufficient number of advocates to entitle it to rank amongst the legitimate operations of the day.

Gwalior, July, 1863.

\section{DEATH FROM PRESSURE.}

\section{By WILLIAM STORY, Esq., F.R.C.S.}

THE following accident occurred on board the ship Norfolk, on her passage to England from Australia. I have not heard or read of a similar catastrophe :-

On the 25th of February, 1863, two men named William Joyce and Isaac Watkins were sent aloft to rig out the top. gallant studding-sail boom; and while in the act of so doing, a tremendous roll of the ship caused the main-topsail tie to part, the tie being an iron chain of three quarters of an inch. The men were standing on the foot-rope, and when the snap took place they instinctively seized hold of the yard, and were instantly rolled up in the folds of the sail, the topsail yard being one of "Cunninghau's patent self-reefing yards;" in fact, they revolved round the yard jnst as a fly might be caught in a patent spring window-blind, and were enveloped as rapidly. The tie parting on the fore side caused the yard to revolve for wards, which would not have been the case had the tie parted on the aft side; it would then have revolved backwards. But the most singuiar circumstance is, that alongside of the yard is what is called the chafing-yard, being only six inches from the yard itself, and the men wrapped in every fold of the sail had to pass, every time the yard revolved, between this yard and the yard itself. At first sight it would seem that every bone in their bodies must have been crushed; yet this was not so. When the yard fell on the cap, which it could not have been more than one second in reaching, both men were alive, al. though surrounded by four or five folds of the sail; and to show the fearful pressure they must bave undergone, one man's head and shoulders had burst through the canvas being nearly a new sail. An idea of the pressure may be gained by putting a narrow piece of tape once round the finger, when very little pressure is felt ; but add five or six turns, and the pain becomes unbearable. On being cut ont of to them their winding sheet, as I said above, both were alive. Watkins died while being lowered to the deck in a sling, and carefully guarded by two of his mates. On examining his body, which I did twice, I was surprised to find only a comminuted fracture of the left thigh bone, without any external abrasion or wound. His ribs were perfect, and the appearance was that of suffocation. The other man (Joyce) was perfectly sensible, but pnlseless, cold, and clammy when I examined him, which was after he had been put into the captain's swing cot. He said he felt something burst in his belly. Every thing was done to promote re. action, but without effect, and he sank nineteen hours after the accident, perfectly conscious. The only injuries I could detect were a comminuted fracture of the right thigh bone, and an abrasion of the skin over the right temporal region, where his head had burst through the sail.

And now comes the question, How is it only one bone in each man's body was broken after having passed several times through two rollers, almost similar to a patent mangle, only of gigantic dimensions? On instituting further inquiries, I ascertained that the chafing yard would possibly give from four to six inches as the bodies passed between it and the main yard. This would give from ten to twelve inches at most as the space through which they passed. Death seemed to be from intense shock.

It would have been satisfactory to have made a post-mortem examination, and I made a request to the captain to this effect; but from the severity of the weather, and the superstitious fears of the sailors, he begged of me not to do it. Not the 